\title{
Special Interests and Technological Change
}

\author{
Giorgio Bellettini ${ }^{y} \quad$ Gianmarco I.P. Ottavianoz
}

J uly 30, 1999

\begin{abstract}
A bstract
We model an OLG economy where productivity growth comes from two alternative sources: process innovation and learning-by-doing. There is a trade-ox between the two in so far as frequent technological updates reduce the scope for learning on existing technologies. A confict is shown to arise between the young and the old, because the former favor innovation while the latter prefer learning. We model the interaction between dixerent generations and short-lived policy makers as a dynamic common agency problem, where competing generations invest a certain amount of resources to lobby either for the maintainance of the current technology or the adoption of a new one. By focusing on truthful Markov perfect equilibria, we characterize the political equilibrium and show its dependence on the underlying technological parameters.
\end{abstract}

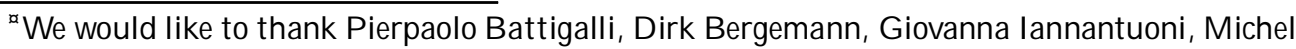
Lebreton, Andrea Prat, J osé-Victor Rios-Rull and Jacques Thisse for helpful comments and suggestions.

'yellettini: Dipartimento di Scienze Economiche, Università di Bologna. Tel. +39-0512098661, fax: +39-051-2098040, e-mail: belletti@economia.unibo.it.

ZOttaviano: Dipartimento di Scienze Economiche, Università di Bologna. Tel. +39-0512098666, fax: +39-051-2098040, e-mail: ottavian@economia.unibo.it
} 


\section{Introduction}

"the country that is more developed industrially only shows, to the less developed, the image of its own future" (Karl Marx)

As pointed out by Lucas (1988) in his breath-taking manifesto, one the greatest challenges to economic thinking is to understand the origins of large international income dixerences, the reason being that such wide dixerences - of factor 30-40 between the tails of the per capita income levels distribution - seem to signal the existence of huge unexploited possibilities for improving human welfare. A decade after, even if our understanding has made important steps forward, the challenge is still there (Prescott, 1998). On the one side, neoclassical growth theory has driven our attention to international dixerences in the stocks of productive factors. However, simple growth accounting exercises show that dixerences in such stocks could explain dixerences in per capita income levels only if investment in intangible assets (e.g. human and organizational capital) were implausibly large - in some instances, as large as GDP. On the other side, new growth theory has stressed the role of international dixerences in endogenously accumulated stocks of usable knowledge as signalled by dixerences in total factor productivities. However, this perspective clashes with the observed absence of clear national biases in international absolute labor productivities across sectors: after all, if workers in one country were better educated or had better work practices than workers in another country, the former should be more productive than the latter in all sectors. Therefore, dixerences in the stocks of factors and of usable knowledge provide only a partial explanation of international income discrepancies.

P rescott (1998) argues that, in order to complete the explanation, it is not usable knowledge in itself that has to be considered but rather the amount of usable knowledge that is actually used. Total factor productivities dixer because countries dixer in terms of their ability to adopt or fully exploit newer and newer available technologies, or what K indleberger (1962) calls "the capacity to transform". Because new technology adoption induces structural changes whose acceptance requires to trade ox short term adjustment sacri..ces against long term ed ciency gains, the capacity to transform is largely determined by the composition of 'progressive' and 'conservative' conficting interests ("the clash between progress and security", Fisher, 1935). Under this perspective, the wealth of nations comes 
to depend on the ec cacy of institutional interest intermediation processes that lead to national decision making. This vision is strongly supported by historical evidence (Olson, 1982; Gilpin 1987; Mokyr, 1990). A classical example of the failure of institutional interest intermediation is the inertial explanation of the decline of $\mathrm{G}$ reat B ritain as the world hegemonic economic power towards the end of the nineteenth century: "Britain was caught in a set of ideological traps. All the strategies available to her were blocked ox in one way or another" (Lewis, 1978). The vision is also broadly consistent with evidence coming from international sectorial analyses (e.g., Clark, 1987; B aily, 1993; Wolcott, 1994; Baily and Gersbach, 1995) and business-oriented case studies which point out how ideological traps may oppose the development of ..rms 'competitive advantage' through technological upgrading (Porter, 1990).

Our aim is to investigate how ideological traps blocking the adoption of new technologies may arise from unbalanced interest representation as well as shortsighted decision making and, thus, to suggest that international dixerences in total factor productivity may be linked to international discrepancies in the mechanics of political intermediation between conservative and progressive interests.

To capture in a simple way such a clash between conservative and progressive interests, we model an OLG economy where productivity growth comes from two alternative sources: process innovation and learning-by-doing. There is a tradeox between the two insofar as frequent technological updates reduce the scope for learning on existing technologies. A confict is shown to arise between the young and the old, because the former favor innovation while the latter prefer learning. Under this respect, the economics of the paper is much in the spirit of K rusell and Rios-R ull's (1996) path-breaking contribution based on the vintage human capital model of Chari and Hopenhayn (1991). However, in order to make our point as clear as possible, we use the streamlined version of that work as presented by Aghion and Howitt (1998). The idea is simple. At each point in time there is an incumbent vintage of an aggregate technology. Such a vintage can either be still improvable or obsolete. In the former case, learning-by-doing can enhance its productivity, in the latter the scope for learning is exhausted. Also at each point in time there is a new vintage, which is freely available and, if adopted, becomes more productive than the old one only after some running in. This initial productivity gap is the more severe the less learning has taken place on the previous vintage. Therefore, there is a trade-ox between innovation 
and learning-by-doing, which creates a potential conłict of interests between the young and the old who, due to their dixerent life horizons, tend to favor innovation and learning by doing respectively.

A more signi..cant departure from the existing literature is made in terms of interest intermediation. Both Krusell and Rìos-Rull (1996) and Aghion and Howitt (1998) assume that the intergenerational conłict is handled by democratic voting so that the interests of the larger generation prevail. While an enlightening ..rst step, this approach is unsatisfactory for two main reasons. First, when technological change is involved, public intervention usually takes the form of government regulation in areas such as product and security standards, environmental policy, restrictions on entry, and trade barriers, which are the realm of organized interest group action rather than of democratic voting (V iscusi, Vernon and Harrington, 1993). Second, by attributing an overwhelming role to demographic factors, democracy somehow obscures the underlying economic stances. ${ }^{1}$ For both reasons, we model an alternative mechanism of interest intermediation, based on the action of organized interest groups, that will be shown to yield a resolution of the intergenerational conłict in which economic factors play a relevant role. In so doing, we build on the ideas of Olson (1965) who argues that what matters for the success of special interest groups are the relative surpluses that they are able to generate for their members, rather than their relative demographic sizes. His insights have been recently formalized in terms of a common agency set-up where, in the wake of Bernheim and W hinston (1986), competing interest groups (principals) lobby an incumbent policy maker (agent) in order to inłuence her decisions (see, e.g., Grossman and Helpman, 1994; Dixit, Grossman and Helpman, 1997; Grossman and Helpman, 1998). ${ }^{2}$ The policy maker knows the ec cient decision to make for the living generations, but she is assumed to trade ox aggregate welfare against special interests.

While our work is deeply rooted in the common agency approach to politics, we depart from its standard implementation under one major respect that brings

\footnotetext{
${ }^{1}$ From an empirical point of view, this feature may also clash with the insigni..cance of demographic variables often found in growth regressions (Levine and Renelt, 1992).

${ }^{2}$ See also the elegant foundation by Grossman and Helpman (1996) who introduce lobbies in a democratic environment where competing ideologically oriented parties use campaign contributions from aligned groups of voters in order to win seats in parliament. Such contributions are spent to infuence the voting behavior of uninformed (not aligned) citizens.
} 
us back to the original menu auction of Bernheim and Whinston (1986). We like to think of our regulator (auctioneer) as being uninformed and with no personal preferences over alternative policy choices. Moreover, her decision making is (possibly slightly) costly so that inertia is the policy outcome in the absence of any external stimulus. Interest groups (bidders) understand the potential role of their activities (menus of oxers) in fostering the implementation of their favorite policies and are willing to use resources to make themselves heard. The strengths of their competing exorts transmit their private information to the policy maker. In our simple framework, this means that competing generations invest a certain amount of resources in supporting either the maintenance of the current vintage technology or the adoption of the new one. In doing so, they expect the policy maker to implement the alternative, whose support absorbs the larger amount of resources. Therefore, our characterization of special interest politics is essentially dixerent from the one based on inłuence/ campaign driven contributions (Tullock, 1967; K rueger, 1974; B hagwati, 1982; B ecker, 1983; Snyder, 1990) even in its recent common agency formulation and it is closer to the idea of informational lobbying (Banks and Weingast, 1992; A insworth, 1993; A usten-Smith and Wright, 1992 and 1994; Lohmann, 1995), which views interest groups as sources of information for imperfectly informed politicians.

As in Grossman and Helpman (1998), political myopia is embedded in the model by assuming that regulators stand in o $\$$ ce for one period only. This leads to the characterization of the mechanics of interest intermediation in each moment as a menu auction game between a one-period-lived auctioneer and two overlapping generations of bidders. We are not aware of any study of such a game and even related results are scarce. Bergemann and Välimäki (1998a) analyze a repeated common agency game with imperfect observability. They also investigate a dynamic common agency game with in..nitely-lived players and propose the Truthful Markov Equilibrium concept that we also adopt (Bergemann and Välimäki, 1998b). Grossman and Helpman (1998) characterize the Markov Perfect Equilibrium of a common agency game in which there are overlapping generations but only the older is exogenously assumed to act as an active principal. Moreover, while their policy space is continuous, our technology adoption choice is inherently binary. This discrete feature will be shown to give rise to 
endogenous lobby formation. ${ }^{3}$

By assuming for simplicity that auctioneers maximize total bids and perfect information on the side of the bidders (Bernheim and W hinston, 1986), we are able to show that, ..rst, the winner of the auction is the interest group that is able to generate the larger relative surplus for its members independently from its size. Second, because of perfect information, the expected loser does not organize any collective action. Third, the winner's exort absorbs an amount of resources which is equal to the relative surplus that the losing group would obtain were it to chose the policy (second-price) so that, provided that existing generations have free access to the lobbying process, the outcome is ed cient from their point of view. This result, which is a corollary of well-known properties of auctions ( $\mathrm{R}$ iley and Samuelson, 1981; B ernheim and Whinston, 1986; Wolfstetter, 1996), is reminiscent of the ec ciency argument by Wittman (1989) who sustains that competing uninformed political entrepreneurs have all the incentives to discover and exploit unknown political demands. Fourth, the identity of the winner depends crucially on the underlying economic parameters. Fifth, a cycle which involves periods of stagnation being followed by periods of technological change may arise endogenously from the competing actions of organized interest groups. Sixth, such economic cycle is accompanied by an endogenous political cycle of lobbies formation. Seventh, because policy makers are short-lived and living generations do not take into account the impact of their choices on all future generations, in general the political outcome is dynamically inec cient from the point of view of future generations. Therefore, unbalanced interest representation and shortsighted decision making lead to inec cient technological trajectories.

The implication of our analysis is that international income dixerences could be traced back to more or less severe problems of interest representation and policy makers' planning horizons. Interestingly enough, since, due to more contained free rider problems and incumbent advantages, more concentrated and betterestablished interests are likely to face substantially lower costs of collective action than more dixuse and recent ones (Olson, 1965; Bendor and Mookerjee, 1987), our analysis also suggests that extended democratic mandates can be interpreted as a 'second-best' political solution that sacri..ces some information about the personal intensities of citizens' preferences ('intensive information') in favor of

\footnotetext{
${ }^{3} \mathrm{~N}$ onetheless, as G rossman and Helpman (1998), we assume away the problem that free riding creates to the organization of collective action (OIson, 1965).
} 
wider participation to the policy making process ('extensive information') (Dahl, 1994).

The remainder of the paper consists of four additional sections. The ..rst introduces the model. After presenting the political equilibrium concept, the second solves the model and comments on the el ciency of the policy outcome. The third studies the emergence of endogenous economic and political cycles in relation to the underlying parameters. The fourth concludes.

\section{The model}

\subsection{E conomics}

Consider an overlapping generations framework consisting of agents who live for two periods only. At any moment in time two generations are alive: the old $\mathrm{O}$ and the young $\mathrm{Y}$ with lifetime horizons of one and two periods respectively. Population grows at a costant rate $n$.

Each generation is made of homogeneous agents. At birth the lifetime preferences of the representative agent born at time $t$ are represented by the following intertemporal utility function:

$$
u^{t}=c_{t}^{t}+1 / \varepsilon_{t+1}^{t}
$$

where $c_{s}^{t}$ is consumption at time $s$ of the agent born at $t$ and $1 / 22(0 ; 1)$ is the discount factor.

Independently from their generation, all agents supply inelastically one unit of the sole factor of production, say labor $L$, which is employed to produce a unique consumption good $X$ under constant returns to scale. At any point in time per-capita output is given by:

$$
x_{t}=, A^{\circledR}
$$

where $x_{t}$ is the output share of each individual alive at time $t$, and, $A{ }^{\circledR}$ is labor productivity. The ..nal good cannot be stored and there are no capital markets. Thus, in each period and for each generation, consumption equals disposable income.

Labor productivity improves in time due to process innovation. Progress comes in the form of new vintages $®$ of technology. Each vintage induces an 
improvement of size A $2(1 ; 1)$. However, the full exploitation of a new vintage technology requires learning-by doing. In particular, we assume that learning takes one period so that, $2(0 ; 1)$ when the new vintage is introduced and, = 1 after one period. M oreover, part of the learning obtained on the old vintage spills over to the new vintage:,$=\ldots$ if learning-by-doing did not occur on the old vintage, and,$=-{ }_{-}$, if it occurred.

A ccordingly, when deciding whether to substitute the existing vintage $®$ with the new vintage ${ }^{\circledR}+1$, agents may face a trade-ox between the productivity gains of learning-by-doing and those of process innovation. In particular, this is the case if:

$$
\text { A }<<1<{ }^{-} A
$$

The existence of a trade-ox between innovation and learning-by-doing creates a potential intergenerational conłict. The old, who will not be there next period, may prefer the current productivity gains arising from learning on the existing vintage. On the contrary, the young, who will be alive next period, may like to trade such gains for future productivity improvements stemming from current innovation.

\subsection{Politics}

Innovation policy is the outcome of a process of interest intermediation by public regulators. Regulators are assumed to be short-lived in that they remain in charge for one period only and they are all identical (Grossman and Helpman, 1998). On the one hand, they have no inherent preferences about policies and are a priori unaware of the existence as well as the potential of new vintages so that, when left alone, they maintain the status quo technology. On the other hand, they can be forced into action by special interests.

We model the mechanism of interest intermediation as a common agency game. Each generation has the opportunity of getting organized as a pressure group in order to inłuence the regulator's decision through collective activities. These activities may materialize in support demonstrations or in various sorts of direct and indirect side-payments to the incumbent regulator, such as bribes and campaign contributions. Due to coordination problems, such collective activities absorb resources. Only if a pressure group spends a positive amount of resources, the regulator is able to hear its voice. The eф cacies of collective activities depends 
only on the amount of resources spent and neither the identity nor the size of the corresponding interest group. This amounts to assuming, ..rst, that the 'pressure formation function', which maps a group's lobbying expenditures into regulator's payou, exhibits constant returns to scale as well as unitary unit input coec cient and, second, that the regulator's payox is a simple sum of groups' collective expenditures.

The speci..c mechanism we consider is a ..rst-price menu-auction game (B ernheim and Whinston, 1986) in which each period the regulator selects an action and each lobby of the living cohorts oxers a menu of contributions contingent on the action chosen. The lobbies pay their announced contributions for the allocation ultimately chosen by the regulator and this choice is made to maximize the regulator's payox, given the menus of oxers announced. A complication with respect to the original set-up by Bernheim and W hinston (1986) comes from the fact that, in choosing their contributions at time $t$, the young must look ahead to period $t+1$. This is because they will still be around and their future consumption will be axected by both the policy adopted and the contributions paid at that time.

In principle, this game has a potentially large set of equilibria. To limit their number, we restrict our attention to Nash equilibria which are both 'truthful', in that the corresponding contributions correctly rełect relative preferences for the various alternatives and $M$ arkov-perfect in that, in a stationary environment, expected policies are not only self-ful...ling but also depend only on the values of the state variable expected at that time (K rusell and Rìos-Rull, 1996). ${ }^{4}$

Speci..cally, we extend the common agency model of Bernheim and Whinston (1986) to a dynamic setting. In each period there are three players: an agent (the regulator) and two principals (the lobbies of the currently young and old). Players are short-lived. The regulator lives one period only and so does the lobby of the currently old. The lobby of the currently young becomes next period old lobby. Therefore, we have a dynamic common agency set-up with one-period-lived agents and overlapping generations of principals. $^{5}$

\footnotetext{
${ }^{4}$ Truthful $\mathrm{N}$ ash equilibria are appealing because they are the only $\mathrm{N}$ ash equilibria that are stable when nonbinding communication is possible. Moreover, as we will see, they have strong e屯 ciency properties.

${ }^{5}$ Short-lived agents and overlapping generations of principals dixerentiate our extension from the dynamic common agency game with in..nitely lived players studied by Bergemann and
} 
Time is discrete and is denoted by $t=0 ; 1 ;: ; ; 1$. The lobbies are indexed by i $2 \mathrm{I}=\mathrm{fY}$; Og. In each period the regulator can select an action (policy) pt $2 \mathrm{P} 2 \mathrm{fl} ; \mathrm{Ng}$ where $\mathrm{I}$ and $\mathrm{N}$ stand respectively for 'innovation' and 'no innovation'. Each lobby oxers a reward scheme (contribution) $r_{i}\left(p_{t} ; z_{t}\right) 2 R_{+}^{2}$ which depends on the history $z_{t}$ and the action $p_{t}$ chosen by the regulator in period $t$. Let $r_{t}{ }^{\prime}\left(r_{O}\left(I ; z_{t}\right) ; r_{O}\left(N ; z_{t}\right) ; r_{Y}\left(I ; z_{t}\right) ; r_{Y}\left(N ; z_{t}\right)\right)$ be the list of lobbies' contributions in period $t, p^{\prime}\left(p_{0} ;:: ; p_{t} ;:::\right)$ be the list of policies chosen in each period and $r^{\prime}\left(r_{0} ;: ; ; r_{t} ;:::\right)$ be the list of the lists of lobbies' contributions in each period.

The history of the game in period $t$ is $z_{t}{ }^{\prime}\left(p_{0} ; \ldots ; p_{t_{1} 1} ; r_{0} ; \ldots ; r_{t_{i} 1}\right)$ and $Z_{t}$ is the set of all possible t period histories. The future in period $t$ is the sequence of future actions $\left(p^{t} ; r^{t}\right)=\left(p_{t+1} ;:: ; r_{t+1} ;:::\right)$. We denote by $Z\left(z_{t}\right)$ the set of all possible histories $Z_{t+1}$ which are accessible from history $Z_{t}$, and analogously $Z\left(p_{t} ; z_{t}\right)$ the set of all possible histories $\mathrm{Z}_{\mathrm{t}+1}$ generated by $\mathrm{Z}_{\mathrm{t}}$ and $p_{\mathrm{t}}$. B oth actions $\mathrm{I}$ and $\mathrm{N}$ can be implemented by the regulator at no cost and no inherent personal bene.t. On the contrary, they are not indixerent to the lobbies. The instantaneous fow bene.t of regulator's action $p_{t}$ to lobby $i$ is $v_{i}\left(p_{t} ; z_{t}\right)$.

A reward strategy for lobby $i$ is a mapping $r_{i}: P f Z_{t} ! R_{+}^{2}$ which assigns to every possible action $\mathrm{p}_{\mathrm{t}} 2 \mathrm{P}$ of the regulator a nonnegative reward contingent on the past history of the game. A strategy for the regulator is an action $p$ : $R_{+}^{2} f Z_{t}$ ! $P$ which depends on the aggregate reward in period $t$.

With history $z_{t}$ the expected payox for the regulator of an action $p_{t}$ is the total reward raised: $r_{O}\left(p_{t} ; z_{t}\right)+r_{Y}\left(p_{t} ; z_{t}\right)$. The expected payo for the old lobby is the current $\ddagger$ ow bene..t net of the regulator's reward:

$$
n_{O}\left(p_{t} ; z_{t}\right)^{\prime} v_{O}\left(p_{t} ; z_{t}\right) \text { i } r_{O}\left(p_{t} ; z_{t}\right)
$$

while the expected payox of the young lobby also includes the expected nextperiod $\neq$ ow bene.t $V\left(p_{t} ; z_{t}\right)$ if in period the action was $p_{t}$ and history was $z_{t}$ :

$$
n_{Y}\left(p_{t} ; z_{t}\right)^{\prime} v_{Y}\left(p_{t} ; z_{t}\right) i r_{Y}\left(p_{t} ; z_{t}\right)+1 / 2\left(p_{t} ; z_{t}\right)
$$

To reduce the number of potential equilibria, we restrict our attention to strategies that in any period $t$ do not depend on the entire history of the game $z_{t}$, but only on the previous period regulator's action $p_{t_{i}}$ (Markov strategies) Välimäki (1998). 
and that in addition are 'truthful' (Bernheim and Whinston, 1986; Bergemann and Välimäki, 1998b). Notice that the previous period regulator's action is the "natural" choice as the state variable of the economy, since current payous (and therefore current actions) depend crucially on whether in the previous period there was a technological change or not.

De..nition 1. A markovian reward strategy $r_{i}\left(p_{t} ; p_{t_{i}}\right)$ for lobby $i$ is said to be truthful with respect to $\left(\boldsymbol{p}_{i} p_{t_{i} 1}\right)$ if and only if for all $p_{t} 2 P$, either

(i) $n_{i}\left(p_{t} ; p_{t i 1}\right)=n_{i}\left(p ; p_{t i 1}\right)$

or

(ii) $n_{i}\left(p_{t} ; p_{t_{i} 1}\right)<n_{i}\left(p_{i} ; p_{t_{i} 1}\right)$, and $r_{i}\left(p_{t} ; p_{t_{i} 1}\right)=0$.

Accordingly, we propose the following recursive de..nition of the equilibrium of our dynamic political common agency game:

De..nition 2. The strategies $r_{O}^{\alpha}\left(p_{t} ; p_{t_{i} 1}\right), r_{Y}^{\alpha}\left(p_{t} ; p_{t_{i} 1}\right)$ and $p^{\alpha}\left(r(:) ; p_{t ; 1}\right)$ form a Markov Perfect Equilibrium (MPE) in truthful strategies if and only if:

(i) for all $p_{t_{1} 1}$ and all $r(:), p^{\alpha}\left(r(:) ; p_{t_{1} 1}\right)$ is a solution to

$$
\operatorname{maxf}_{p_{t} 2 P} r_{O}\left(p_{t} ; p_{t_{i} 1}\right)+r_{Y}\left(p_{t} ; p_{t_{i} 1}\right) g
$$

(ii) for all $p_{t_{i} 1}$, there is no other reward function $b_{0}\left(p_{t} ; p_{t_{i} 1}\right)$ such that

$$
\mathrm{n}_{\mathrm{O}}\left(\mathrm{p}_{\mathrm{i} ; \mathrm{p}_{\mathrm{i}} 1}\right)>\mathrm{n}_{\mathrm{O}}\left(\mathrm{p}_{\mathrm{t}}^{\mathrm{\alpha}} ; \mathrm{p}_{\mathrm{t}_{\mathrm{i}} 1}\right)
$$

where $\mathrm{p}^{\alpha}$ and $\mathbf{p}$ are best response actions to $\left(r_{O}^{\infty}(:) ; r_{Y}^{\alpha}(:)\right)$ and $\left(b_{O}(:) ; r_{Y}^{\alpha}(:)\right)$ respectively.

(iii) for all $p_{t i 1}$, there is no other reward function $r_{Y}\left(p_{t} ; p_{t_{i} 1}\right)$ such that

$$
\mathrm{n}_{Y}\left(\bar{p}_{t} ; p_{t_{i} 1}\right)>n_{Y}\left(p_{t}^{\alpha} ; p_{t_{i} 1}\right)
$$

where $p^{\alpha}$ and $p$ are best response actions to $\left(r_{O}^{\not a}(:) ; r_{Y}^{a}(:)\right)$ and $\left(r_{O}^{\alpha}(:) ; r_{Y}(:)\right)$ respectively.

(iv) $r_{O}^{\mathfrak{\alpha}}(:)$ and $r_{Y}^{\mathfrak{a}}(:)$ are truthful strategies with respect to $p^{\alpha}(:)$.

\section{The political equilibrium}

Operationally, the characterization of the set of truthful equilibria requires the evaluation of the young lobby's next-period expected bene.t $V\left(p_{t} ; z_{t}\right)$. Such evaluation can be done by following De..nition 2 , which implies that the two dixerent 
triples of players, who are active in two dixerent periods $t_{1}$ and $t_{2}$, will take the same equilibrium actions when confronted with the same history $p_{t_{1 i} 1}=p_{t_{2 i} 1}$. This restricts the set of candidate equilibria to those entailing only four alternative patterns of technological change $\left(p_{t} ; p_{t_{i}}\right) 2 \mathrm{f}(\mathrm{I} ; \mathrm{I}) ;(\mathrm{N} ; \mathrm{I}) ;(\mathrm{I} ; \mathrm{N}) ;(\mathrm{N} ; \mathrm{N}) \mathrm{g}$.

The following result applies:

Proposition 1. A ssume $A_{\perp}>$, and de. ne $R_{i t}=r_{i t} A^{-}$where ${ }^{-}={ }_{t}^{P}{ }_{s=0} F_{s}$ with $F_{S}=1$ for $p_{S}=I$ and $F_{S}=0$ for $p_{S}=N$. Then

(i) $\left(R_{O t}^{\alpha} ; R_{Y t}^{\alpha} ; p^{\alpha}\right)=[0 ;(1 ;, A) ; I]$ when $p_{t i 1}=I$ and $\left(R_{O t}^{\alpha} ; R_{Y t}^{a} ; p^{\alpha}\right)=[0 ; " ; I]$ when $p_{t_{i} 1}=N$ is the only MPE in truthful strategies if and only if

$$
1 / 2>\frac{2+n}{1+n} \frac{\left(1 i_{+} A\right)}{A\left(A_{2},\right)}
$$

(ii) $\left(R_{O t}^{\alpha} ; R_{Y t}^{\alpha} ; p^{\alpha}\right)={ }^{f} A\left(1+A^{1} / 2 i 1 ; 1 / 3 A ; 0 ; N^{\alpha}\right.$ when $p_{t i 1}=I$ and $\left(R_{O t}^{\alpha} ; R_{Y t}^{\alpha} ; p^{\alpha}\right)=$ $\left[0 ; " ;\right.$ I ] when $p_{t_{i} 1}=N$ is the only MPE in truthful strategies if and only if:

$$
\frac{\left(1 i_{\perp} A\right)}{A\left(A_{i}{ }_{\lrcorner}\right)}<1 / 2<\frac{2+n}{1+n} \frac{\left(1 i_{\perp} A\right)}{A\left(A_{i}{ }_{\lrcorner}\right)}
$$

(iii) $\left(R_{O t}^{\alpha} ; R_{Y t}^{\alpha} ; p^{\alpha}\right)=[0 ; 0 ; N]$ when $p_{t_{1} 1}=1$ and $\left(R_{O t}^{\alpha} ; R_{Y t}^{\alpha} ; p^{\alpha}\right)=[0 ; " ; I]$ when $p_{t_{1} 1}=N$ is the only MPE in truthful strategies if and only if:

$$
1 / 2<\frac{(1 ;, A)}{A\left(A_{i} i_{J}\right)}
$$

P roof. The game is a ..rst-price menu auction where the winner pays the secondhighest bid (Bernheim and Whinston, 1986). First, we can rule out candidates for equilibrium where both $O$ and $Y$ contribute. If both lobbies want the same policy, only one will contribute an in..nitely small amount ". This is what is meant by $R_{O t}^{\alpha}=0$ and $R_{Y t}^{\alpha}="$. On the other hand, if their interests con $\neq i c t$, only the winning lobby contributes, while the other, realizing that it cannot win, does not contribute at all.

Second, we can rule out candidates for equilibrium with $p_{t}=N$ when $p_{t_{i} 1}=$ $\mathrm{N}$, the reason being that, when the current state is $\mathrm{N}$, both groups bene.t from innovation. Thus, all equilibria, must have $p_{t}=I$ whenever $p_{t_{i} 1}=N$.

Third, $p_{t}=1$ with only $Y$ contributing is the equilibrium outcome when

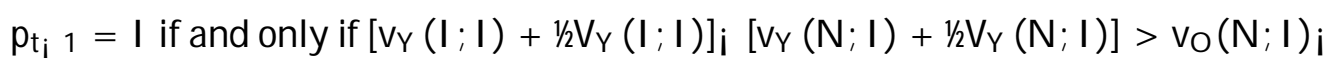
$v_{O}(I ; I)>0$. This explains condition (3.1). 
Fourth, $p_{t}=\mathrm{N}$ with only $\mathrm{O}$ contributing is the equilibrium outcome when $\mathrm{p}_{\mathrm{t}_{\mathrm{I}} \mathrm{I}}=\mathrm{I}$ if and only if $\mathrm{v}_{\mathrm{O}}(\mathrm{N} ; \mathrm{I}) \mathrm{i}_{\mathrm{i}} \mathrm{v}_{\mathrm{O}}(\mathrm{I} ; \mathrm{I} \mathrm{I})>\left[\mathrm{v}_{Y}(\mathrm{I} ; \mathrm{I})+{ }^{1} / \mathrm{S}_{Y}(\mathrm{I} ; \mathrm{I})\right]_{\mathrm{i}}\left[\mathrm{v}_{Y}(\mathrm{~N} ; \mathrm{I})+{ }^{1 / B / Y}(\mathrm{~N} ; \mathrm{I})\right]>$ 0 . This explains condition (3.2).

Fifth, $p_{t}=\mathrm{N}$ with neither group contributing is the equilibrium outcome when $p_{t_{i} 1}=I$ if $v_{O}(N ; I)$ i $v_{O}(I ; I)>\left[v_{Y}(N ; I)+1 / d / Y(N ; I)\right]_{i}\left[v_{Y}(I ; I)+1 / / / Y(I ; I)\right]>$ 0 . This explains (3.3).

In other words, there are three alternative MPE in truthful strategies depending on parameter values. In one equilibrium, which occurs when condition (3.1) is satis..ed, innovation takes place at every point in time and learning-by-doing never takes place. When (3.1) holds, restless technological update is sustained by the organized collective action of the young. In a second equilibrium, which occurs when condition (3.2) is satis..ed, a period of technological update is followed by a period of stagnation and viceversa. Growth alternatively relies on innovation and learning-by-doing. When (3.2) holds, technological change is blocked every second period by the organized collective action of the old. The same kind of technological cycle characterizes the third equilibrium, which occurs when condition (3.3) is satis..ed. The dixerence with respect to the previous case is that, when (3.3) holds, technological change is triggered every second period by the organized collective action of either lobby. In any case, in both the second and third equilibria, technological change is accompanied by endogenous cycles of lobbies' formation.

It is worthwhile noticing that, because strategies are truthful, the MPE entails the step-wise maximization of lobbies' welfare. However, the MPE will be generally inec cient from a dynamic point of view due to the fact that short-sighted regulators and overlapping generations' lobbies do not take into account that current technological choices axect future regulators' payox and future generations' welfare. As shown by Bergemann and Välimäki (1998b) dynamic eł ciency of dynamic common agency games requires in..nite planning horizons.

\section{Comparative statics}

In this section, we study how the political equilibria that we characterized in P roposition 1 depend on the subjective discount factor $1 / 2$ on the rate of growth of population $n$ and on the technological parameters,, , and $A$. To derive our results, we will focus on the relevant trade-ox faced by dixerent generations in 
their choice of lobbying for the implementation of a new technology versus the continuation of the existing one.

As we discussed in the previous section, only strategies and actions when the history of the game is I need to be analyzed. In the other case, when previous period action was $\mathrm{N}$, the only possible equilibrium policy is to innovate, which is the preferred policy of both lobbies. More speci..cally, we will study if, following a change in the above parameters, the political equilibrium where technological change occurs in every period is more or less likely to occur relative to the equilibrium cycle, where periods of innovations and periods of technological rest alternate.

First of all, we will now argue that when the intertemporal discount rate decreases, equilibrium cycles where periods of technological innovations follow periods of stagnation are more likely to occur. Assume that the state of the game is I. If innovation takes place in the current and in the next period, the discounted value of next period bene.t for the young is given by $1 / 2 A^{\circledR+2}$ : If instead, no innovation occurs in the current period (and obviously innovation does take place in the next one), the discounted value of next period bene..t is given by $1 / 3 A^{\circledR+1}$. Given our assumptions, $1 / 2, A_{i},{ }^{-\Phi}>0$ so that the higher is $1 / 2$ the more likely that the young will lobby for continuous innovations.

Let us now consider how the equilibrium changes when the degree of positive externality from the learning by doing on the old technology to the productivity of the new technology changes. This positive externality is represented by the parameter , : Intuitively, when ${ }^{-}$increases (decreases), it should be less (more) likely that agents choose to innovate in every period. By looking at condition (3.1) (which is the necessary and suc cient condition for innovation to arise in every period), we can easily see that this is indeed the case.

When _changes, future productivity gains that are independent from the full exploitation of current technology change as well. If _ increases (and therefore future productivity gains also increase), we would expect agents to ..nd continuous technological innovation relatively more attractive. A gain, inspection of condition (3.1) shows that this anticipation is correct. Finally, notice that the changes in the parameter $A$ are economically similar to changes in ... Thus, their exects on the equilibrium can be explained in the same way.

To conclude, changes in the rate of population growth $\mathrm{n}$ axects the politicoeconomic equilibrium because they alter the relative size of the lobbies. The 
higher is $\mathrm{n}$ the larger is the lobby of the young and the larger is their aggregate contribution relative to the contribution of the old. Thus, the equilibrium with continuous innovations is more likely to arise when the rate of growth of population is high.

\section{Conclusion}

In this paper, we constructed a model where the interaction between organized special interests and the policy makers generates a political equilibrium which involves either continuous process innovations or periods of technological change followed by periods of stagnation (i.e. technological cycles). The prevailing equilibrium depends on technological and preference parameters, and not only on the demographic structure of the population as it happens in 'democratic' models. M ore speci..cally, equilibrium technological cycles are likely to arise when agents put little value on future consumption, when the positive externality on future productivity gains of current learning-by-doing is high and when the future productivity gains that do not depend on the full exploitation of current technology are low. In any case, technological change is accompanied by endogenous cycles of lobbies' formation and, because the interests of future generations are not taken into account, it will be generally inec cient from a dynamic point of view. International income dixerences could be traced back to more or less severe problems of interest representation and policy makers' planning horizons.

\section{R eferences}

[1] Aghion, P., and P. Howitt (1998) Endogenous Growth Theory (Cambridge (Mass.): MIT Press).

[2] A insworth, S. (1993) Regulating lobbyists and interest groups in uence, J ournal of Politics 55, 41-56.

[3] A usten-Smith, D. and J .R. Wright (1992) Competitive lobbying for a legislator's vote, Social Choice and W elfare 9, 229-257.

[4] A usten-Smith, D. and J .R. Wright (1994) Counteractive lobbying, A merican J ournal of Political Science 38, 25-44. 
[5] Bailey, M.N. (1993) Competition, regulation, and the ect ciency in service industries, Brookings Papers on Economic Activity, 71-130.

[6] Bailey, M.N. and H. Gersbach (1995) E $\phi$ ciency in manufacturing and the need for global competition, B rookings Papers on Economic Activity, 307347.

[7] Banks, J . and B.R. Weingast (1992) The political control of bureaucracies under asymmetric information, A merican J ournal of Political Science 36, 509-524.

[8] Becker, G.S. (1983) A theory of competition among pressure groups for political inłuence, Quarterly J ournal of E conomics 98, 371-400.

[9] Bendor, J . and D. M ookherjee (1987) Institutional structure and the logic of ongoing collective action, American Political Science Review 81, 129-154.

[10] Bergemann, D. and J. Välimäki (1998a) Repeated Common A gency and Imperfect Observability, mimeo, N orthwestern and Yale University.

[11] Bergemann, D. and J . Välimäki (1998b) Dynamic Common A gency, Cowles Foundation Discussion Paper N 0.1206, Yale University.

[12] Bernheim, B.D. and M.D. W hinston (1986) M enu auctions, resource allocation, and economic inłuence, Q uarterly J ournal of E conomics 101, 1-31.

[13] Bhagwati, J.N. (1982) Directly unproductive, pro..t-seeking (DUP) activities, J ournal of Political Economy 90, 988-1002.

[14] Chari, V.V . and H. Hopenhayn (1991) Vintage human capital, growth and the dixusion of new technology, J ournal of P olitical Economy 99, 1142-1165.

[15] Dahl, R.A. (1994) A democratic dilemma: System exectiveness and citizen participation, Political Science Quarterly 109, 23-34.

[16] Dixit, A.K., G. Grossman and E. Helpman (1997) Common agency and coordination: General theory and application to government policy making, J ournal of Political Economy 105, 753-769.

[17] Fisher, A . (1935) The Clash of Progress and Security (London: Macmillan). 
[18] Gilpin, R. (1987) The Political E conomy of International Relations (Prince ton: Princeton University Press).

[19] Grossman, G. and E. Helpman (1994) Protection for sale, American Economic Review 84, 833-850.

[20] Grossman, G. and E. Helpman (1996) Electoral competition and special interest politics, Review of Economic Studies 63, 265-286.

[21] Grossman, G. and E. Helpman (1998) Intergenerational distribution and short-lived governments, Economic J ournal 108, 1299-1329.

[22] Kindleberger, C.P. (1962) Foreign Trade and the National Economy (New Haven: Yale University Press).

[23] K rueger, A . (1974) The political economy of the rent-seeking society, A merican E conomic Review 64, 291-303

[24] K rusell, P., and J .-V. Rìos-Rull (1996) Vested interests in a positive theory of stagnation and growth, Review of Economic Studies 63, 301-329.

[25] Krusell, P., V. Quadrini and J .-V. Rìos-Rull (1997) Politico-economic equilibrium and economic growth, J ournal of E conomic Dynamics and Control 21, 243-272.

[26] Levine, R. and D. Renelt (1992) A sensitivity analysis of cross country growth regressions, American Economic Review 82, 942-963.

[27] Lewis, A. (1978) Growth and Fluctuations, 1870-1913 (London: George Allen and Unwin).

[28] Lohman, S. (1995) Information, access and contributions: A signaling model of lobbying, Public Choice 85, 267-284.

[29] Mokyr, J. (1990) The Lever of Riches: Technological Creativity and Economic Progress (New York: Oxford University Press).

[30] OIson, M. (1965) The Logic of Collective Action: Public Goods and the Theory of Groups (Cambridge (Mass.): Harvard University Press).

[31] Olson, M. (1982) The Rise and Decline of Nations - Economic Growth, Stagł ation, and Social Rigidities (New Haven: Yale University Press) 
[32] Porter, M.E. (1990) The Competitive Advantage of Nations (London: M acmillan Press).

[33] Prescott, E.C. (1998) Needed: A theory of total factor productivity, International Economic Review 39, 525-551.

[34] Riley, J.G. and W.F. Samuelson (1981) Optimal auctions, American Economic Review 71, 381-392.

[35] Snyder, J .M. (1991) On buying legislatures, Economics and Politics 3, 93109.

[36] Tullock, G. (1967) The welfare costs of tariæs, monopolies and theft, Western Economic J ournal 5, 224-232.

[37] Viscusi, W .K., Vernon, J .V. and J .E. Harrington (1993) Economics of Regulation and Antitrust (D.C. Heath and Company).

[38] Wittman, D. (1989) Why democracies produce eç cient results, J ournal of Political Economy 97, 1395-1424.

[39] Wolfstetter, E. (1996) Auctions: An Introduction, J ournal of Economic Surveys $10,367-420$. 